\title{
A Study of Nurses' Internal, External, and Social Images as Perceived by College Students in South Korea
}

\author{
Yoon Heun Keung ${ }^{1}$ \\ ${ }^{1}$ Department of Nursing, Howon Unversity, Gunsan, South Korea \\ Correspondence: Yoon Heun Keung, 64 Howondae 3gil, Impi, Gunsan-Si, Jeollabuk-do, 54058, Korea. Tel: \\ 82-63-450-7114; Fax: 82-63-450-7769. E-mail: yhk9874@hanmail.net
}

Received: October 16, 2017 Accepted: November 19, 2017 Online Published: December 18, 2017

doi:10.5539/gjhs.v10n1p156 URL: https://doi.org/10.5539/gjhs.v10n1p156

\begin{abstract}
Purpose: This study is a descriptive survey study aiming to examine the internal, external, and social images of nurses as perceived by Korean college students and clarifying the relationship between these images.

Methods: This study was performed using a structured questionnaire from May 2 to 14, 2016. Data were collected from 221 college students and were statistically interpreted using t-test, one-way ANOVA, and Pearson's correlation coefficient.

Results: The study results are as follows: First, the internal image of nurses was scored at 3.46 points, the external image at 2.78, and the social image at 2.76. Second, a significant positive correlation was found between the internal, external, and social images as well as between the external and social images, implying the importance of both internal and external images of nurses.
\end{abstract}

Conclusion: The results of this study are expected to be used as a reference base for devising strategies and measures for the enhancement of internal, external, and social images of nurses for future healthcare consumers.

Keywords: internal image, external image, social image, nurse image, college students

\section{Introduction}

Nursing care has become widely recognized as a profession (Choi \& Ha, 2009) and the image of nursing care and of nurses has been changed positively (Seong, Yeom, \& Do, 2014) as the varied and independent roles of nurses have been recently required in nursing care for patients.

This image of nursing care contributes to raising nurses' status and developing nursing science. Despite the role of nurses as a profession, nursing students perceive the image of nurses negatively because of perceptions regarding a socially insufficiently recognized profession, lack of autonomy and independence, and difficult and hard work (Seong, Yeom, \& Do, 2014). Medical service consumers persistently stereotype images of nurses' work because they still consider nurses as angels in white who passively act out doctors' orders (Shin, 2015). Although nursing is recognized as a profession that demonstrates expertise and skill, its social image is found to be associated with relatively low perceptions as a profession to encourage family and relatives or to have a good social status (Park \& Park, 2014). Since these consumers have such low perceptions of nurses, this may reduce job satisfaction among nurses and have a negative influence on the quality of nursing care (Roberts \& Vasquez, 2004). Measures need to be devised to promote the correct awareness of nurses to themselves and future medical service consumers.

Image affects thinking and behaviors by existing in an individual's thoughts as an aggregation of human beliefs, thoughts, and impressions toward a certain subject and is a factor that forms attitudes (Song, Park, \& Wee, 2015). It is essential for college students to understand the image of nurses from multiple perspectives before experiencing medical services in the future. Furthermore, image has a substantial impact on work performance by building perceptions and attitudes toward a career (Lee et al., 2016). Since the public perception towards nurses can influence the job performance of nurses (Yom, Kim, Son, Lee, \& Kim, 2015), efforts to identify the current status of nurses' image are needed. However, most previous studies on the image of nurses' were comprised solely of nursing students (Park \& Park, 2014; Seong, Yeom, \& Do, 2014); only a few studies have involved college students as future medical service consumers.

Understanding of image classification and image-building factors is essential to analyze the image of nurses. 
Image is categorized into internal image, external image, and social image (Kim, 2006). Internal image is composed of self-concept, cognitive and emotional factors, and character and propensity factors. Previous studies on nurses' image have focused predominantly on internal image. External image comprises physical, expressive, behavioral and auditory factors. Few studies have explored behavioral and auditory factors, and there have been no studies which have examined expressive factors. Social image consists of communication, manner, etiquette and others. A recent study has attempted to investigate social image as perceived by nurses themselves in relation to professional values (Song, 2008). In summary of the above findings, previous studies on nurses' image have mainly focused on internal image as the general image seen in mass communication, books, and advertisements. Only a few studies have been performed on social image, and almost no studies have examined external image. Moreover, few studies have included college students as future medical service consumers. These studies, by being limited to nursing college students, have mostly identified factors affecting nursing professional values (Cho \& Kim, 2014; Seong, Yeom, \& Do, 2014). Therefore, multilateral research is warranted to further explore nurses' internal, external, and social images in detail as well as to identify the relationships between these images in the present era where the role of nurses has expanded greatly in future medical service consumers. This primary aim of this study is to investigate college students' perceptions of the internal, external, and social images of nurses and the relationship between these images.

This study aims to investigate the degree of perception of internal, external, and social images of nurses among college students, and to clarify the relationship between these images to provide a reference base for devising measures to improve nurses' image. The study purposes are as follows:

First, this study aims to identify the degree of college students' perception of the internal, external, and social images of nurses.

Second, this study aims to identify differences in college students' perception of the internal, external, and social images of nurses according to their general characteristics.

Third, this study aims to identify the correlation between the internal, external, and social images of nurses as perceived by college students.

\section{Methods}

\subsection{Design, Participants and Data Collection Procedures}

This study is descriptive survey that investigates the relationship between nurses' internal, external, and social images as perceived by college students.

Subjects were selected through convenience sampling among college students attending two 4-year colleges located in S and I cities. All subjects consented to participation in this present study after being fully informed of the research goals. Data were collected for 14 days, beginning on May 2, 2016. Data were collected from college students who consented to participate in the study after gaining approval from department chairs and student representatives of each college. A total of 250 questionnaires were returned. Twenty-nine questionnaires with inadequate or unresponsive items were excluded. The remaining 221 questionnaires were used for the analysis. The sample size calculation was performed using $\mathrm{G}^{*}$ Power 3.1.3 program. Sample size calculations indicated that the appropriate sample size was 128 with an effect size of $25 \%$, a significance level of $5 \%$, and a power of $95 \%$ (Faul, Erdfelder, Lang, \& Buchner, 2007). Therefore, a sample size of 221 questionnaires was appropriate for statistical analysis in this study.

To increase college student participation, investigators announced the data collection schedule and the location of the survey after explaining the research goals, confidentiality/anonymity of collected data, compensation for research participation and others. Moreover, college students who consented to voluntary participation were asked to fill out a consent form and a structured questionnaire at a designated place. Completed questionnaires were sealed and stored inside an unmarked envelope to avoid involuntary participation due to an authoritarian relationship between professors and students as well as protecting the right of self-determination concerning research participation.

\subsection{Instruments}

\subsubsection{Internal Image of Nurses}

Internal image implies intrinsic image, which includes consciousness and emotion created internally; the internal image consists of self-concept, cognitive and emotional factors, character and propensity (Kim, 2006). This study used 15 items, from an assessment scale developed by Kang, Go, Yang, and Kim (2003), to measure the internal image of nurses, excluding items concerning social image. Advice was sought from three professors in the College 
of Nursing regarding the validity of the modified questionnaire, and reliability of the tool was assessed. The assessment tool used consisted of 6 items on professional image, 6 items on traditional image, and 3 items on job prospects for nursing. These items were rated on a five-point Likert scale from 1 (not at all) to 5 (very much). The score of the nurses' internal image represents the average for the total score of items (score range: 1-5 points). A higher mean score indicates a higher level of perception by college students on the internal image of nurses. Reliability of the scale was high with a Cronbach's alpha of 0.94 from a previous study and a Cronbach's alpha of 0.95 in this study.

\subsubsection{External Image of Nurses}

External image means phenomenal image in which inner nature is comprehensively expressed externally. The external image is comprised of physical, expressive, behavioral and auditory factors (Kim, 2006). This study used 18 items from an assessment scale developed (Jeong, 2002) for the measurement of make-up image of nurses. For measuring the external image of nurses, each item of this assessment tool was scored on a four-point Likert scale from 1 (not at all) to 4 (quite a lot). Comparably, the score of nurses' external image represents the average total score of each item (score range: 1-4 points). A higher mean score indicates a higher level of perception of the external image of nurses. Reliability of the scale was high with a Cronbach's alpha of 0.92 in a previous study (Jeong, 2002) and a Cronbach's alpha of 0.94 in our study.

\subsubsection{Social Image of Nurses}

Social image implies the relationship in which self-nature and phenomena are manifested and formed as relative exchange in interpersonal relations. Social image includes social environment, communication, manner, etiquette and the level of interpersonal relations (Kim, 2006). For measurement of social image of nurses, this study used an attitude scale for nurses developed by Jeong (2002). This scale is composed of 10 items about college students' feelings about nurses' attitudes, and these items were rated on a four-point Likert scale from 1 (not at all) to 4 (quite a lot). The score represents the average of total scores (score range: 1-4 points). A higher mean score indicates a better social image toward nurses. Reliability of the scale was measured with a Cronbach's alpha of 0.85 in a previous study (Jeong, 2002), and a Cronbach's alpha of 0.85 in our study.

\subsection{Data Analysis}

Collected data were analyzed using PASW Window version 20.0, and two-tailed p-values were considered significant at $p<0.05$. First, variables related to the general characteristics of the subjects were analyzed with actual numbers, percentages, means and standard deviations. Second, differences in the internal, external, and social images of nurses, according to the subjects' general characteristics, were tested using t-test and one-way ANOVA. Post-hoc analysis was performed using Scheffe's test. Third, correlations between nurses' internal, external, and social images in the subjects were analyzed with Pearson's correlation coefficient.

\section{Results}

\subsection{General Characteristics of the Subjects}

In regards to general characteristics, sophomores accounted for the largest percentage (52.0\%), while freshmen accounted for the smallest percentage (10.9\%). The percentages of male and female students were $13.1 \%$ and $86.9 \%$, respectively. Approximately $29.4 \%$ of the subjects majored in culinary arts, $27.1 \%$ majored in dental hygiene and beauty art each, and $16.3 \%$ majored in airline services. For $17.2 \%$ of the students, a family member was a nurse in and $51.1 \%$ had a history of hospital admission (Table 1). 
Table 1. General Characteristics of Subjects $(\mathrm{N}=221)$

\begin{tabular}{lll}
\hline Characteristics & Category & $\mathrm{n}(\%)$ \\
\hline Grade & Freshman & $24(10.9)$ \\
& Sophomore & $115(52.0)$ \\
& Junior & $50(22.6)$ \\
& Senior & $32(14.5)$ \\
\hline Sex & Male & $29(13.1)$ \\
& Female & $192(86.9)$ \\
\hline Major & Food \& Cookery & $65(29.4)$ \\
& Dental \& Hygiene & $60(27.1)$ \\
& Fashion \& Beauty & $60(27.1)$ \\
& Aviation Service & $36(16.3)$ \\
\hline Nurses in the family & Yes & $38(17.2)$ \\
& No & $183(82.8)$ \\
\hline History of admission & Yes & $113(51.1)$ \\
& No & $108(48.9)$ \\
\hline
\end{tabular}

\subsection{Degree of Perceptions on Internal, External, and Social Image of Nurses}

The average score for nurses' internal image as perceived by college students was 3.46 points (range, 1-5). The mean scores were 3.62 in professional image, 3.42 in traditional image, and 3.29 rated the lowest, in job prospects for nursing. With respect to professional image, scores were 3.72 for a question on 'Nurses possess abundant expert knowledge', 3.69 for a question on 'Nurses have a high intellectual level', and 3.66 for a question on 'Nurses perform duties in an organized and orderly manner'. In regards to traditional image, scores were 3.48 for a question on 'Nurses explain and answer in simple terms for better understanding', and 3.43 for a question on 'Nurses treat patients without prejudice', higher than the mean score. The score of career prospects for nursing was high at 3.71 for a question on 'Nursing is a promising profession'.

The average score for nurses' external image was 2.78 points (range, 1-4). The scores of questions were 3.00 for 'Nurses are clean', 3.00 for 'Nurses are neat', 2.95 for 'Nurses look modern', 2.92 for 'Nurses present a professional appearance', and 2.91 for 'Nurses fit for work characteristics'.

The mean score for nurses' social image was 2.76 points (range, 1-4). The scores of questions were 3.04 for 'Attire is neat', 2.96 for 'Nurses have professional pride in their work', and 2.81 for 'Nurses are calm and feminine', higher than the mean score for that category (Table 2).

Table 2. Perceptions of College Students on the Internal, External and Social Image of Nurses $(\mathrm{N}=221)$

\begin{tabular}{|c|c|c|c|c|}
\hline \multicolumn{3}{|c|}{ Variables } & \multicolumn{2}{|l|}{$\mathrm{M} \pm \mathrm{SD}$} \\
\hline \multirow{6}{*}{$\begin{array}{l}\text { Internal } \\
\text { image }\end{array}$} & \multirow{6}{*}{$\begin{array}{l}\text { Professional } \\
\text { image }\end{array}$} & Nurses properly deal with emergencies. & $3.64 \pm 0.76$ & \multirow[t]{6}{*}{$3.62 \pm 0.74$} \\
\hline & & Nurses possess abundant expert knowledge. & $3.72 \pm 0.77$ & \\
\hline & & Nurses perform duties in an organized and orderly manner. & $3.66 \pm 0.81$ & \\
\hline & & Nurses have a high intellectual level. & $3.69 \pm 0.79$ & \\
\hline & & Nurses have highly skilled expertise. & $3.65 \pm 0.83$ & \\
\hline & & Nurses give a sense of trust. & $3.59 \pm 0.87$ & \\
\hline
\end{tabular}




\begin{tabular}{|c|c|c|c|}
\hline \multirow{6}{*}{$\begin{array}{l}\text { Traditional } \\
\text { image }\end{array}$} & Nurses are kind. & $3.39 \pm 0.88$ & \multirow[t]{6}{*}{$3.42 \pm 0.76$} \\
\hline & $\begin{array}{l}\text { Nurses explain and answer in simple terms for better } \\
\text { understanding. }\end{array}$ & $3.48 \pm 0.85$ & \\
\hline & Nurses treat patients without prejudice. & $3.43 \pm 0.82$ & \\
\hline & Nurses are friendly to patients and their family. & $3.42 \pm 0.87$ & \\
\hline & Nurses deserve to be called as angels in white. & $3.25 \pm 0.97$ & \\
\hline & Nurses work conscientiously and are honesty. & $3.44 \pm 0.84$ & \\
\hline \multirow{3}{*}{$\begin{array}{l}\text { Career } \\
\text { prospects for } \\
\text { nursing }\end{array}$} & Nursing is a profession to encourage family or relatives. & $3.29 \pm 1.04$ & \multirow[t]{3}{*}{$3.29 \pm 0.87$} \\
\hline & Nursing is a promising profession. & $3.71 \pm 0.90$ & \\
\hline & Nurses have high social status. & $3.30 \pm 0.92$ & \\
\hline
\end{tabular}

\begin{tabular}{|c|c|c|}
\hline & Average & $3.46 \pm 0.74$ \\
\hline \multirow{19}{*}{$\begin{array}{l}\text { External } \\
\text { image }\end{array}$} & Nurses present a professional appearance. & $2.92 \pm 0.52$ \\
\hline & Nurses fit for work characteristics. & $2.91 \pm 0.53$ \\
\hline & Nurses look dignified. & $2.74 \pm 0.63$ \\
\hline & Nurses look intellectual. & $2.80 \pm 0.61$ \\
\hline & Nurses appear enthusiastic. & $2.79 \pm 0.63$ \\
\hline & Nurses give us comfort. & $2.76 \pm 0.63$ \\
\hline & Nurses give a sense of friendliness. & $2.78 \pm 0.63$ \\
\hline & Nurses look gentle. & $2.78 \pm 0.63$ \\
\hline & Nurses look cheerful. & $2.78 \pm 0.65$ \\
\hline & Nurses are sophisticated and stylish. & $2.72 \pm 0.68$ \\
\hline & Nurses stand out on sight. & $2.63 \pm 0.65$ \\
\hline & Nurses do not appear to be tired. & $2.63 \pm 0.69$ \\
\hline & Nurses are neat. & $3.00 \pm 0.54$ \\
\hline & Nurses are clean. & $3.00 \pm 0.53$ \\
\hline & Nurses look modern. & $2.95 \pm 0.55$ \\
\hline & Nurses look caring. & $2.79 \pm 0.65$ \\
\hline & Nurses are elegant. & $2.85 \pm 0.58$ \\
\hline & Nurses make us feel uncomfortable..$^{\dagger}$ & $2.63 \pm 0.80$ \\
\hline & Average & $2.78 \pm 0.49$ \\
\hline \multirow{11}{*}{$\begin{array}{l}\text { Social } \\
\text { image }\end{array}$} & Nurses speaks gently with soft facial expression. & $2.70 \pm 0.60$ \\
\hline & Attire is neat. & $3.04 \pm 0.54$ \\
\hline & Nurses have professional pride in their work. & $2.96 \pm 0.54$ \\
\hline & Nurses are cold and formal..$^{\dagger}$ & $2.30 \pm 0.66$ \\
\hline & Nurses look tensed and stiff. ${ }^{\dagger}$ & $2.57 \pm 0.70$ \\
\hline & Nurses are kind. & $2.78 \pm 0.60$ \\
\hline & Nurses are very human. & $2.80 \pm 0.59$ \\
\hline & Nurses are elegant and graceful. & $2.59 \pm 0.65$ \\
\hline & Nurses are affectionate and familiar. & $2.71 \pm 0.65$ \\
\hline & Nurses are calm and feminine. & $2.81 \pm 0.63$ \\
\hline & Average & $2.76 \pm 0.55$ \\
\hline
\end{tabular}

\footnotetext{
${ }^{\dagger}$ Reversed items.
} 


\subsection{Differences in the Internal, External, and Social Images of Nurses by the General Characteristics of Subjects}

No significant difference was found in the internal image of nurses according to gender, presence of a nurse as a family member, or history of hospital admission. On the contrary, there was a significant difference by grade level $(\mathrm{F}=6.71, \mathrm{p}=<.001)$ and major $(\mathrm{F}=7.40, \mathrm{p}=<.001)$. The results of Scheffe's post-hoc analysis by grade level indicated that seniors had a significantly lower score (2.95) when compared to freshmen (3.54), 3.59 in sophomores and 3.47 in juniors. With respect to major, score was significantly higher (3.81) in culinary arts students when compared to dental hygiene students (3.26) and beauty art students (3.33).

No significant difference was found in the external image of nurses in regards to the presence of a nurse as a family member or a history of hospital admission. However, a significant difference was demonstrated by grade level $(\mathrm{F}=20.19, \mathrm{p}=<.001)$, gender $(\mathrm{t}=2.66, \mathrm{p}=.008)$, and major $(\mathrm{F}=14.01, \mathrm{p}=<.001)$. Results of post-hoc analysis by grade level indicated seniors had a significantly lower score (2.32) compared to freshmen (2.77), sophomores (2.92), and juniors (2.80). With respect to major, score was significantly lower in dental hygiene (2.52) compared to culinary arts (2.99), beauty art (2.84), and airline services (2.79). There was no significant difference in the social image of nurses in regards to the presence of a nurse as a family member or history of hospital admission. On the other hand, a significant difference was shown by grade level $(\mathrm{F}=19.76, \mathrm{p}=<.001)$, gender $(\mathrm{t}=3.47,<\mathrm{p}=.001)$, and major $(\mathrm{F}=13.68, \mathrm{p}=<.001)$. Post-hoc analysis results by grade level revealed that seniors had a significantly lower score (2.32) when compared to freshmen (2.78), sophomores (2.87), and juniors (2.74). With respect to major, score was significantly higher in culinary arts (2.95) when compared to airline services (2.75), and dental hygiene (2.53) (Table 3).

Table 3. Differences in the Internal and External and Social Image of Nurses according to General Characteristics of Research Subjects $(\mathrm{N}=221)$

\begin{tabular}{|c|c|c|c|c|c|c|c|}
\hline \multirow[t]{2}{*}{ Characteristics } & \multirow[t]{2}{*}{ Category } & \multicolumn{2}{|c|}{ Internal image } & \multicolumn{2}{|c|}{ External image } & \multicolumn{2}{|c|}{ Social image } \\
\hline & & $\mathrm{M} \pm \mathrm{SD}$ & $\mathrm{F} / \mathrm{t}(p)$ & $\mathrm{M} \pm \mathrm{SD}$ & $\mathrm{F} / \mathrm{t}(p)$ & $\mathrm{M} \pm \mathrm{SD}$ & $\mathrm{F} / \mathrm{t}(p)$ \\
\hline \multirow[t]{4}{*}{ Grade } & Freshman $^{\mathrm{a}}$ & $3.54 \pm 0.67$ & 6.71 & $2.77 \pm 0.39$ & 20.19 & $2.78 \pm 0.38$ & 19.76 \\
\hline & Sophomore $^{\mathrm{b}}$ & $3.59 \pm 0.73$ & $(<.001)$ & $2.92 \pm 0.39$ & $(<.001)$ & $2.87 \pm 0.34$ & $(<.001)$ \\
\hline & Junior $^{\mathrm{c}}$ & $3.47 \pm 0.60$ & $\mathrm{~d}<\mathrm{a}, \mathrm{b}, \mathrm{c}$ & $2.80 \pm 0.31$ & $\mathrm{~d}<\mathrm{a}, \mathrm{b}, \mathrm{c}$ & $2.74 \pm 0.31$ & $\mathrm{~d}<\mathrm{a}, \mathrm{b}, \mathrm{c}$ \\
\hline & Senior $^{\mathrm{d}}$ & \multicolumn{2}{|l|}{$2.95 \pm 0.85$} & \multicolumn{2}{|l|}{$2.32 \pm 0.46$} & \multicolumn{2}{|l|}{$2.32 \pm 0.47$} \\
\hline \multirow[t]{2}{*}{ Sex } & Male & $3.46 \pm 0.78$ & -0.04 & $2.99 \pm 0.48$ & 2.66 & $2.99 \pm 0.40$ & 3.47 \\
\hline & Female & $3.46 \pm 0.74$ & (.997) & $2.76 \pm 0.39$ & $(.008)$ & $2.72 \pm 0.39$ & $(.001)$ \\
\hline \multirow[t]{4}{*}{ Major } & \multicolumn{2}{|l|}{ Cookery $^{a}$} & \multirow{4}{*}{$\begin{array}{l}(<.001) \\
\text { b.c }<a\end{array}$} & $2.99 \pm 0.44$ & $\begin{array}{l}14.01 \\
(<.001)\end{array}$ & $2.95 \pm 0.32$ & $\begin{array}{l}13.68 \\
(<.001)\end{array}$ \\
\hline & $\begin{array}{l}\text { Dental \& } \\
\text { Hygiene }^{\mathrm{b}}\end{array}$ & $3.26 \pm 0.82$ & & $2.52 \pm 0.37$ & $\mathrm{~b}<\mathrm{a}, \mathrm{c}, \mathrm{d}$ & $2.53 \pm 0.45$ & $\mathrm{~b}<\mathrm{d}<\mathrm{a}$ \\
\hline & $\begin{array}{l}\text { Fashion } \\
\text { Beauty }^{c}\end{array}$ & $3.33 \pm 0.62$ & & $2.84 \pm 0.37$ & & $2.78 \pm 0.37$ & \\
\hline & $\begin{array}{l}\text { Aviation } \\
\text { Service }^{\mathrm{d}}\end{array}$ & $3.42 \pm 0.71$ & & $2.79 \pm 0.39$ & & $2.75 \pm 0.26$ & \\
\hline \multirow{2}{*}{$\begin{array}{l}\text { Nurses in } \\
\text { the family }\end{array}$} & Yes & $3.63 \pm 0.67$ & 1.51 & $2.83 \pm 0.42$ & 0.52 & $2.80 \pm 0.35$ & 0.76 \\
\hline & No & $3.43 \pm 0.76$ & $(.132)$ & $2.78 \pm 0.44$ & $(.964)$ & $2.74 \pm 0.30$ & $(.450)$ \\
\hline \multirow{2}{*}{$\begin{array}{l}\text { History of } \\
\text { admission }\end{array}$} & Yes & $3.47 \pm 0.76$ & 0.15 & $2.81 \pm 0.46$ & 0.69 & $2.76 \pm 0.38$ & 0.36 \\
\hline & No & $3.46 \pm 0.74$ & $(.880)$ & $2.77 \pm 0.41$ & $(.492)$ & $2.74 \pm 0.42$ & $(.720)$ \\
\hline
\end{tabular}

${ }^{\dagger} \mathrm{a}, \mathrm{b}, \mathrm{c}, \mathrm{d}=$ Post-Hoc test.

\subsection{Correlations between Internal, External and Social Image of Nurses}

A significant positive correlation was observed between nurses' internal image and external image as perceived by the subjects $(\mathrm{r}=.518, \mathrm{p}=<.001)$. A significant positive correlation was also found with social image $(\mathrm{r}=.522$, $\mathrm{p}<.001)$. External image showed a statistically significant positive correlation with the subscales of internal image 
including professional image $(\mathrm{r}=.483, \mathrm{p}<.001)$, traditional image $(\mathrm{r}=.555, \mathrm{p}<.001)$, and prospect image $(\mathrm{r}=.752$, $\mathrm{p}<.001)$.

Social image had a statistically significant positive correlation with these subscales, professional image $(\mathrm{r}=.504$, $\mathrm{p}<.001)$, traditional image $(\mathrm{r}=.575, \mathrm{p}<.001)$, and prospect image $(\mathrm{r}=.502, \mathrm{p}<.001)$. A statistically significant positive correlation was found between the external image and social image of nurses $(\mathrm{r}=.756, \mathrm{p}=<.001)$ (Table 4$)$.

Table 4. Correlation between Internal and External and Social Image of Nurses $(\mathrm{N}=221)$

\begin{tabular}{lll}
\hline & $\begin{array}{l}\text { External image } \\
\mathrm{r}(p)\end{array}$ & $\begin{array}{l}\text { Social image } \\
\mathrm{r}(p)\end{array}$ \\
\hline Internal image & $.518(<.001)$ & $.522(<.001)$ \\
Professional image & $.483(<.001)$ & $.504(<.001)$ \\
Traditional image & $.555(<.001)$ & $.575(<.001)$ \\
Career prospects for nursing & $.752(<.001)$ & $.502(<.001)$ \\
External image & & $.756(<.001)$ \\
\hline
\end{tabular}

\section{Discussion}

Nurses' image has a profound impact on the professionalism and role performance of nurses. Strategies for proposing and promoting new images of nurses are needed to offer patients high-level health care. This study was performed to provide a reference base for devising various strategies and measures to improve nurses' image by identifying the degree and relationship of nurses' internal, external, and social image as perceived by Korean college students.

The degree of college student perception of internal image of nurses was 3.46 out of a perfect score of 5, indicating a moderate level. There are limitations in directly comparing our study results with the findings of previous studies due to the differing characteristics of the subjects and the assessment tools used. Nevertheless, the score of this research was lower than 3.66 in a study on elementary, junior high, and high school students (Kim \& Kang, 2013), and 3.66 in a study on nursing and general college students (Jeun, No, Ryou, Oh, \& Park, 2015), but slightly higher than 3.29 in a study on ordinary people and patients (Kim, 2002) and 3.36 in a study on junior high and high school students (Lee \& Kim, 2016). These outcomes support previous studies recommending that the internal image of nurses is perceived differently depending on the age and characteristics of the subjects (Lee et al., 2016; Yom, Kim, Son, Lee, \& Kim, 2015). Further investigations are required to establish nurses' image appropriate to the times by exploring how nurses' image varies by age using the same assessment scale. In the subscales of nurses' internal image as perceived by college students, scores were 3.62 in professional image, 3.42 in traditional image, and 3.29 in career prospects for nursing, all of which comparable to those scores of past research (Yoo, 2014). However, scores were lower than average score for the questions on 'Nurses are kind', 'Nurses treat patients without prejudice', 'Nurses are friendly to patients and their family', 'Nurses deserve to be called angels in white', 'Nursing is a profession to encourage family or relatives', and 'Nurses have high social status'. This finding indicates that nurses' past representative images such as kindness, devotion, and angels have been reduced as nurses perform a variety of roles as a specialized job. Thus, highly subdivided and new distinctive images have been built. Therefore, nurses should be equipped with expertise and skills of the nursing profession, educated about building nursing professional values and fostering ethical practice, and character needs to be carried out to pursue the correct professional identity.

The external image score was 2.78 out of a perfect score of 4 , slightly lower than 3.0 in a study on ordinary individuals (Jeung, 2002). Scores were higher than average for questions on 'Nurses are neat', 'Nurses are clean', and 'Nurses look modern', whereas scores were lower than average for questions on 'Nurses look dignified', 'Nurses are sophisticated and stylish', 'Nurses stand out on sight', and 'Nurses do not appear to be tired'. These results imply that college students have perceived that nurses have a neat and clean appearance in performing their roles in hospitals. However, negative images are created by perceiving nurses' image externally as dignified and sophisticated in appearance and having a tired look. A previous study documented that positive image toward outward appearance changes perceptions in a more positive direction about career image (Yom, Kim, Son, Lee, \& Kim, 2015). In regards to the changing needs of medical consumers, as a positive correlation has been revealed between nurses' external image and medical environment (Paek, 2006), ideal image needs to be established in the 
aspects of appearance, make-up and others in practicing professional nursing roles. There were no other previous studies on external image, excluding two past investigations (Jeung, 2002; Paek, 2006), and external favorability needs to be increased in professions requiring trust (Barich \& Kotler, 1991). Additional studies are urgently warranted to confirm nurses' external image in multiple ways.

The score of social image was 2.76 out of a perfect score of 4, higher than 2.11 in a previous study (Jeung, 2002). Scores were high for questions on 'Nurses have professional pride in their work', 'Nurses are very human', and 'Nurses are calm and feminine', but low for questions on 'Nurses are cold and formal', 'Nurses look tensed and stiff', and 'Nurses are elegant and graceful'. These outcomes reveal that external image and social image are linked and externally expressed images including make-up, appearance, attitude, and other factors change inevitably over time. Further studies are required to develop a new assessment scale that reflects current trends. Changes in the social image of nurses these days needs to be further verified and the social image demanded for nurses needs to be prepared through replication studies using a developed scale.

In the analysis of differences in internal, external, and social images, according to the general characteristics of college students, internal image varied by grade level and major. Internal image tended to be low in seniors and high in nursing students. This outcome appears to be attributed to the fact that seniors are more aware of substantial job characteristics when compared to lower grade level students who recognize the general images of nurses by having more opportunities to explore employment-related professions themselves. Our findings were comparable to previous studies in which the internal image of nurses was lower as the grade level became higher (Jo \& Ji, 2004; Kim, 2014; Kim \& Kang, 2013).

In the analysis of differences in external image according to the general characteristics of college students, external image tended to be low among seniors and dental hygiene major students, but high among male students. A decreasing tendency in perceptions on external image with increasing grade level supports previous studies (Kim et al., 2013; Park \& Park, 2014) recommending that internal image was somewhat improved as nurses who perform assigned tasks sincerely in nursing practices have been directly or indirectly exposed through various media, but there was no positive impact on external image. Our result aligns with a previous study (Jeung, 2002) in which nurses' external image as perceived by ordinary people was scored 2.77 in men, which was higher than 2.40 scored in women. Previous studies revealed that men were more likely to feel comfortable and a sense of friendliness through nurses' external image than women, and tended to recognize nurses as professionals and intellectual workers. Since external image is influenced by first impressions regardless of gender, external images including make-up, appearance, attitude need to be built for the delivery of appropriate images. To achieve this goal, attention needs to be focused on re-creating nurses' image by investigating the ideal external image. Meanwhile, the external image of nurses was rated low among dental hygiene major students. This is thought to be attributable to more opportunities to encounter nurses in hospitals during clinical practice when compared to students with other majors. As a result, negative external images appear to be formed, and therefore a range of efforts have to be exerted to improve the external image of nurses. However, only a few studies have been done to identify the external image of nurses; most studies have predominantly focused on the formation of professional image. We need to pay more attention to external image.

Similar to internal and external images, but with respect to differences in social image according to the general characteristics of college students, social image tended to be low among seniors, female students, and dental hygiene major students. Comparable to the findings about external image, the results in this study aligned with those from previous research (Joo \& Shin, 2012), suggesting that college students have a negative image perception of nursing. By recognizing nurses as assistants who passively help doctors' works and practicing limited nursing skills, nurses are perceived as having a low social status. As stated above, prompt attention is required to re-build internal image and establish external and social images of nurses. Furthermore, seamless efforts need to be undertaken for nurses to be recognized as competent professionals capable of providing reliable nursing services in the clinical setting as well as to enhance their asocial status.

In regards to perceptions of college students on nurses' image, a significant positive correlation was found between the internal and external images of nurses, and there was a statistically significant positive correlation with social image. Furthermore, a statistically significant positive correlation was demonstrated between external image and social image. Therefore, new education programs on occupational growth and the social values of the nursing profession need to be developed to build up a positive perception of nurses. For improvement of the external image, new curriculum subjects should be offered on make-up and image-making.

\section{Conclusions}

In this study, internal image as perceived by college students was scored a 3.46, while external image was scored a 
2.78, and social image was scored a 2.76. A strong positive correlation was found between these three variables. The results of this study confirm the importance of traditionally perceived internal image and new external image in improving nurses' image. This study was meaningful in that it explained the necessity of re-formation of the social image for nurses' status and values changing socially over time.

Based on the study results, further studies are recommended to seek strategies and devise measures for the improvement of internal, external, and social images of nurses to future medical service consumers. Moreover, methodological studies are proposed to verify factors that have positive and negative effects on the internal, external, and social images of nurses and to develop an assessment scale for measuring nurses' image that is suitably subdivided to reflect current trends.

\section{Acknowledgments}

The author thanks Wonsun, MiGun Lee and YoonJeung Jang for their help to collect data.

\section{Competing Interests Statement}

The author declare that there are no conflicts of interest.

\section{References}

Barich, H., \& Kotler, P. A. (1991). Framework for marketing image management. Sloan Management Review, 32(2), 94-104.

Cho, H. H., \& Kim, N. H. (2014). Relationships among nursing professionalism, nurse image, and core elements of nursing professionalism that nursing students perceive. Journal of Korean Academic Society of Nursing Education, 20(4), 548-557. https://doi.org/10.11111/jkana.2015. 21.4.435

Choi, J., \& Ha, N. S. (2009). The relationship among image of nurses, self esteem and professional socialization in nursing students. Journal of Korean Academy of Nursing Administration, 15(1), 54-63.

Faul, F., Erdfelder, E., Lang, A. G., \& Buchner, A. (2007). G* Power 3: A flexible statistical power analysis program for the social, behavioral, and biomedical sciences. Behavior Research Methods, 39(2), 175-191. https://doi.org/10.3758/BF03193146

Jeun, E. J., No, Y. M., Ryou, S.M., Oh, S.Y., \& Park, K.S. (2015). Perceived image of nurses on major and non-major students. The Journal of the Korea Institute of Korean Medical Informatics, 21(2), 1-9.

Jeung, I. S. (2002). Study of how nurse makeup effects on medical environment and nurse's image. Unpublished master's thesis. Hansung University. Seoul.

Jo, K., \& Ji, E. S. (2004). Nurse image perceived by students of elementary, middle school students. Journal of East-West Nursing Research, 9(1), 83-90.

Joo, M. K., \& Shin, G. Y. (2012). Nursing image and professionalism perceived by male and female nursing students in college. Journal of Korean Academic Society of Nursing Education, 18(3), 510-521. https://doi.org/10.5977/jkasne.2012.18.3.510

Kang, H. Y., Go, M. H., Yang, J. J., \& Kim, S. M. (2003). Nurses' image perceived by academic and vocational high school teachers in Korea. Journal of Korean Academy of Nursing, 33(6), 792-801. https://doi.org/10.4040/jkan.2003.33.6.792

Kim, H. K. (2002). A general survey on the image of nurse. The Journal of Ewa Nursing Research, 35, 27-45.

Kim, J. E., Jung, H. J., Kim, H. N., Son, S. Y., An, S. K., Kim, S. B., \& Jeon, K. H. (2013). The image of nurses and their clinical role portrayed in Korean medical TV dramas in recent 5 years. Perspectives in Nursing Science, 10(2), 120-132.

Kim, K. H. (2006). A study on establishment of the concept of image-making and the effectiveness analysis of the image-making program. Korean Journal of Youth Studies, 13(1), 269-289.

Kim, Y. J. (2014). Study on the subjectivity about nursing student's image of professional nurse before clinical practice. The Journal of the Korea Contents Association, 14(5), 224-234. https://doi.org/10.5392/JKCA.2014.14.05.224

Kim, Y. M., \& Kang, Y. S. (2013). Nurse's image perceived by elementary, middle and high School students. The Journal of Korean Academic Society of Nursing Education, 19(3), 384-395. https://doi.org/10.5977/jkasne.2013.19.3.384

Lee, H. S. Z., Lee, H. S., Yom, Y.H., Lee, J.M., Jung, W.S., Park, H.J. (2016). A study of the image of nurse 
through analysing linking words of nurse in the internet and social media. Journal of Korean Clinical Nursing Research, 22(2), 173-182. https://doi.org/10.5762/KAIS.2016.17.3.528

Lee, K. K., \& Kim, Y. M. (2016). Social worker's image perceived by middle and high school students: Comparison of the image of social worker and nurse. Journal of the Korea Academia-Industrial cooperation Society, 17(3), 528-536. http://dx.doi.org/10.5762/KAIS.2016.17.3.528

Paek, M. R. (2006). The make-up behavior and the influential factors of nurses in hospitals of Busan. Unpublished master's thesis. Gosin University. Busan. https://doi.org/10.5762/KAIS.2014.15.6.3696

Park, S. J., \& Park, B. J. (2014). Content analysis of nurse images perceived by nursing students. Journal of the Korea Academia-Industrial cooperation Society, 15(6), 3696-3705. http://dx.doi.org/10.5762/KAIS. 2014.15.6.3696

Roberts, D. W., \& Vasquez, E. (2004). Power an application to the nursing image and advanced practice. $A A C N$ Advanced Critical Care, 15(2), 196-204.

Seong, J. A., Yeom, E. Y., \& Do, Y. S. (2014). Image of nurses and nursing professional values perceived by nursing students. The Journal of the Korea Contents Association, 14(11), 798-809. https://doi.org/10.5392/JKCA.2014.14.11.798

Shin, S. Y. (July, 2015). Perception and evolution of nursing images. The Korean Nurse Association News, http://www.nursenews.co.kr/main/eBookView.asp?eBookNum=1917.

Song, E. Y. (2008). An analysis on the effects of facial image-making program to self esteem, positive thinking and facial image efficacy. Unpublished Doctoral Dissertation. Myong-Ji University. Seoul.

Song, M. S., Park, Y. R., \&Wee, H. (2015). Male nurses` images of male students in nursing university. Health and Social Science, 38, 37-67.

Yom, Y. H., Kim, K. H., Son, H. S., Lee, J.M., \& Kim, M. A. (2015). Analysis of the image and likability of the nurse. Journal of Korean Clinical Nursing Research, 21(2), 169-179.

Yu, S. Y. (2014). What is perceived the image of nurses?: Comparison major and non-major students. Journal of digital convergence, 12(10), 353-361. https://doi.org/10.14400/JDC.2014.12.10. 353

\section{Copyrights}

Copyright for this article is retained by the author(s), with first publication rights granted to the journal.

This is an open-access article distributed under the terms and conditions of the Creative Commons Attribution license (http://creativecommons.org/licenses/by/4.0/). 